\title{
ETHzürich
}

ETH Library

\section{Can policy-packaging increase public support for costly policies? Insights from a choice experiment on policies against vehicle emissions}

\section{Journal Article}

Author(s):

Wicki, Michael (1); Huber, Robert A.; Bernauer, Thomas (i)

Publication date:

2020-12

\section{Permanent link:}

https://doi.org/10.3929/ethz-b-000354818

Rights / license:

In Copyright - Non-Commercial Use Permitted

Originally published in:

Journal of Public Policy 40(4), https://doi.org/10.1017/s0143814×19000205

Funding acknowledgement:

295456 - Sources of Legitimacy in Global Environmental Governance (EC) 


\title{
Can Policy-Packaging Increase Public Support for Costly Policies? Insights from a Choice Experiment on Policies against Vehicle Emissions
}

Michael Wicki, ${ }^{* 1}$ Robert A. Huber ${ }^{2}$ and Thomas Bernauer ${ }^{3}$

*Corresponding author

${ }^{1}$ ETH Zurich Institute of Science, Technology and Policy (ISTP) and International Relations (CIS) Universitätstrasse 41 8092 Zürich

Switzerland

michael.wicki@istp.ethz.ch +41446320658

\author{
${ }^{2}$ University of Salzburg \\ Abteilung Politikwissenschaft \\ Rudolfskai 42 \\ 5020 Salzburg \\ Austria \\ robertalexander.huber@sbg.ac.at \\ +4362 80446623
}

\author{
${ }^{3}$ ETH Zurich \\ Institute of Science, \\ Technology and Policy (ISTP) \\ and International Relations \\ (CIS) \\ Haldeneggsteig 4 \\ 8092 Zürich \\ Switzerland \\ thbe0520@ethz.ch \\ +41446326771
}

\begin{abstract}
Public support is usually a precondition for the adoption and successful implementation of costly policies. We argue that such support is easier to achieve with policy-packages that incorporate primary and ancillary measures. We specifically distinguish command-and-control and market-based measures as primary measures and argue that the former will usually garner more public support than the latter given the low visibility tendency of costs associated with command-and-control measures. Nevertheless, if included in a policy-package, ancillary measures are likely to increase public support by reducing negative effects of primary measures. Based on a choice experiment with a representative sample of 2,034 Swiss citizens, we assess these arguments with respect to political efforts to reduce vehicle emissions. The empirical analysis supports the argument that policy-packaging affects public support positively, particularly generating more support when ancillary measures are added. Lastly, we ultimately observe that command-and-control measures obtain more public support than market-based instruments.
\end{abstract}

Keywords: transportation policy, ancillary measures, command-and-control measures, market-based regulation, public opinion, conjoint experiment 


\section{Introduction $^{1}$}

Policy-makers around the world are facing enormous challenges emanating from processes of urbanisation, population growth, and various facets of technological and economic change. Ambitious policies for addressing these challenges usually require public support (Kachi, Bernauer, and Gampfer 2015). ${ }^{i}$ This can particularly result in a trade-off between policy effectiveness and feasibility when policyinterventions have costly implications for a myriad, if not most, of society members (Cherry, Kallbekken, and Kroll 2012; Gunningham and Sinclair 2017; Kallbekken and Sælen 2011). Since far-reaching (i.e. costly) policies required to solve pressing problems may fail to garner enough public support (Cherry, Kallbekken, and Kroll 2012; Gunningham and Sinclair 2017; Pleger, Lutz, and Sager 2018) their enactment and implementation becomes drastically difficult and potentially impossible in some instances. As a result, policy-makers may then adopt policies that are preferred by the majority of people in society (Anderson et al., 2017; Gunningham and Sinclair 2017; Stehr 2015) but do not solve the problem effectively and/or efficiently (Givoni 2014). Ultimately, this raises the question of whether and how could policy-makers overcome this seeming trade-off between effective and popular policies.

One option for mitigating this dilemma between effectiveness in problem solving and political feasibility (public support) is policy-packaging (Givoni 2014; Givoni et al. 2013). Appropriate combinations of different policy measures or instruments into one proposal (a policy-package) aimed at a particular policy goal can be understood as a form of policy-design (Givoni 2014; Howlett and Rayner 2013; Sager, Ingold, and Balthasar 2017). In line with previous research, we argue that such policy-packages can consist of primary measures aimed at the main policy goal, as well as ancillary measures that increase policy feasibility and strengthen the specific policy goal of the package indirectly (Givoni 2014; Givoni et al. 2013; Justen et al. 2014). While tighter emission labels for cars and car admission taxes are examples of primary measures, campaigns that inform the public about the rationale behind specific primary measures, or government

\footnotetext{
${ }^{1}$ Acknowledgments: The authors would like to acknowledge valuable comments from Liam F. Beiser-McGrath, Gracia Brückmann, Lukas P. Fesenfeld, Sergio Guidon, Dennis Kolcava, Vally Koubi, Quynh Nguyen, Lukas Rudolph, Angélica Serrano, Martina Zahno and two anonymous reviewers. An earlier version of this paper has been presented at the Swiss Political Science Association's Annual Conference in Geneva (February 2018). The research for this article was funded by the ERC Advanced Grant 'Sources of Legitimacy in Global Environmental Governance' (Grant: 295456) and supported by ETH Zürich. Replication materials are available at https://doi.org/10.7910/DVN/LUJC8I.
} 
funding for research on fuel efficient cars, are examples of ancillary measures. In this paper, we are particularly interested in whether policy-packaging along these lines could increase public support for costly policies.

Policy-packaging as a method to increase policy support is not a novel conception, in fact, it is rather common in areas where policy-makers struggle to obtain mass public support for ambitious and costly government interventions. Research on congestion pricing has argued that, compared to singular policy measures, policy-packaging increases the chances of policy implementation success (Andersson and Nässén 2016; Justen et al. 2014; Sørensen et al. 2014). In one particular example of policy-packaging, the Swiss Federal Office of Transport in an attempt to enhance public and stakeholder support for a distancerelated heavy vehicle levy, the policy package earmarked revenue transfer to the cantons and provided funding for new rail links across the Alps (Balmer 2005; Sørensen et al. 2014). In the case of this policy, the allocation of revenues turned out to be crucial in making the policy-intervention politically feasible (Sørensen et al. 2014). Notwithstanding, despite the seeming prevalence of policy-packaging predicated on the assumption that it increases political feasibility, research that systematically assesses the impact of policy-packaging on public support and thus political feasibility remains absent.

As mentioned above, we distinguish primary and ancillary measures and categorise primary policy instruments in command-and-control and market-based measures. With regards to primary measures, we follow the argument by Stadelmann-Steffen (2011) that command-and-control measures tend to receive more public support than market-based measures because the costs of the former tend to be less visible. While an example of command-and-control regulation is a ban on a specific product, a simple tax on such item typify a market-based instrument. Inclusion of ancillary measures into a policy-package may directly affect the policy-package's public support, but it may also mitigate the negative effect of primary measures. Altogether, we maintain that ancillary measures can help offset the adverse effects of public support on primary measures and thus display a positive effect on public support for the respective policy-package.

In an attempt to empirically assess these arguments, we carried out a conjoint experiment with a representative sample of 2,034 Swiss citizens that centred on policies that reduce vehicle emissions and promote electric vehicle adoption. We presented study participants with different policy-packages 
which included four primary measures, three ancillary measures, earmarking of tax revenues, and the year of implementation.

Switzerland is a particularly interesting case regarding the impact of policy-packaging on the political feasibility of transportation policies. To begin with, the populace acts as a formal veto player in political decision-making through direct democratic ballots (Stadelmann-Steffen 2011; Tsebelis 2002). Second, transportation is one of the most challenging policy areas globally, and Switzerland is not the exception. High vehicle density in Switzerland is associated with particularly high external costs of road-based transportation (accidents, environmental and health costs), which are estimated to be in the order of 8 billion Swiss francs per year (Federal Office for Spatial Development 2016). ${ }^{i i}$ Moreover, Switzerland is among the worst performers regarding vehicle emissions in Europe (European Environment Agency 2017) and its transportation sector accounts for approximately 30 percent of Swiss greenhouse gas emissions (Federal Office for the Environment 2017). Under these circumstances, the introduction of new transportation policies remains a challenge (Sager 2007). Therefore, we are hereafter interested in whether policy-packaging can boost public support under such difficult conditions.

The empirical analysis confirms that command-and-control measures receive more public support than market-based instruments. Moreover, our results also indicate that the inclusion of ancillary measures directly increases policy-package public support. Nevertheless, we do not find evidence for the hypothesized moderating (indirect) effect of ancillary measures on the relationship between primary measures and public support for a policy-package.

The remainder of this paper is structured as follows. We start by discussing the existing literature and present our theoretical arguments afterwards. Then, we outline our empirical case, transportation policies in Switzerland and present our study design thereon. All this is followed by a presentation and discussion of the empirical findings, as well as a concluding section.

\section{What we know from existing research}

Conventional wisdom holds that variation in policy-design is likely to affect public support for the respective policy. For example, push measures (e.g. threats of punishment for non-compliance, often 
referred to as sticks) are meant to discourage undesired behaviour, whereas pull measures (e.g. subsidies for facilitating policy implementation, often referred to as carrots) are meant to encourage desired behaviour (Bemelmans-Videc, Rist, and Vedung 2011; de Groot and Schuitema 2012; Vedung 1998). Even though this distinction between pull- and push-measures can be very helpful for various purposes, it does not allow us to distinguish policy measures by the mechanism through which they operate. This is of specific interest, as transportation economists often consider pricing schemes as the 'obviously correct' solution mitigating externality problems (Bamberg and Rölle 2003, 235). Therefore, similar to other studies, the one at hand fixates on the distinction between market-based and command-and-control instruments. Stadelmann-Steffen (2011), for instance, examines market-based instruments designed to create incentives for certain types of behaviour and command-and-control measures consisting of bans and rules. The findings confirm the assumption stating that voters are more likely to accept command-and-control measures, rather than market-based instruments (also see Cherry, Kallbekken, and Kroll 2012; for opposite findings, see Pleger 2017).

Why should we, then, be interested in public opinion and public policy support, alongside the impact of policy-design on public policy support? The reason is that public support for policy measures, and thus public opinion, is closely related to government action (Anderson et al., 2017; Cherry, Kallbekken, and Kroll 2012; Jaensirisak, Wardman, and May 2005; Wlezien 1995). Many studies indicate that policy-makers consider public attitudes and preferences and tend to adhere to them throughout the policymaking process. Political feasibility of policy interventions is thus largely a function of public support levels. Not surprisingly then, policy-makers are often (more) concerned about political feasibility than about maximising problem solving effectiveness (Gunningham and Sinclair 1999, 2017). Gunningham and Sinclair $(2017,144)$ argue that "if political acceptability was closely tied to evidence-based policymaking then the gap between such acceptability and effectiveness should be a relatively narrow one". Therefore, one potential mechanism to mitigate the trade-off between problem-solving effectiveness of policies and public support is policy-packaging.

Policy-packaging can be defined in three different, yet related ways (Bemelmans-Videc, Rist, and Vedung 2011). First, vertical packaging combines various measures at different jurisdictional levels to implement a 
core intervention. Second, chronological packaging describes the combination of policy measures in a specific time order. Third, horizontal packaging involves the simultaneous deployment of two or more measures that aim at the same policy target. In this paper, we are entirely concerned with horizontal packaging. Thereby, we examine how the combination of various primary and ancillary measures could enhance public support. Specifically, we follow Givoni et al. $(2013,3)$ who argue that policy-packages are

"a combination of policy measures designed to address one or more policy objectives, created in order to improve the effectiveness of the individual policy measures, and implemented while minimizing possible unintended effects, and/or facilitating interventions' legitimacy and feasibility in order to increase efficiency."

In academic research, interest in policy-packaging first emerged as part of the economic policy literature on how fiscal and monetary policy interact (Flanagan, Uyarra, and Laranja 2010; Mundell 1962). Ever since, policy-packaging has gained more scholarly attention. Some of the examined policy areas include agriculture (Pereira et al. 2018), air pollution (Lehmann 2010), climate (Kern, Kivimaa, and Martiskainen 2017; Nissinen et al. 2015), environment (Barton et al. 2017), resource efficiency (Bontoux and Bengtsson 2016; Ekvall et al. 2016), tobacco control (Mavrot, Hadorn, and Sager 2018; World Health Organization 2008), transportation (Givoni 2014), and urban freight (Marcucci et al. 2017). iii While this literature focusses mainly on questions of policy-design and how packaging policies might affect policy outcomes by improving policy effectiveness of single policy instruments, Givoni (2014) provides an analytical framework for the study of policy-packaging essential for the development of this paper. He implicitly criticises the strong focus on effectiveness of policy-design and encourages further research on the political feasibility of policies. He argues that policy-packages, especially with the inclusion of ancillary measures, can help to successfully implement policies (also see Givoni et al. 2013). Altogether, given that a central component of successful implementation is public support, policy-packaging is conceivably one way to increase support by combining policy instruments.

Several studies suggest that consolidating politically contested measures with more popular ones within a policy package may facilitate adoption and implementation of the desired policy. On this topic, Milkman et al. (2012) indicate that policy-packaging could help overcome loss aversion and increase political 
feasibility. Providing alternatives to the regulated behaviour (e.g., improving public transportation while increasing fuel taxation at the same time within the package), on the other hand, could further increase public support (Cherry, Kallbekken, and Kroll 2014; Kallbekken and Aasen 2010). Despite perceivable benefits, the implications of policy-packaging for public support levels and, thus, political feasibility have received scarce attention this far (Drews and van den Bergh 2016).

Among the few studies on this issue, Sørensen et al. (2014) examine how the use of revenues from tollroad payment for public-transport services or new road infrastructure eases implementation. The authors qualitatively study three examples of road pricing and associated policy-packaging: the London congestion charging package, the Stockholm congestion tax package, and the Swiss national heavy vehicle fee package. In all three examples, measures that were likely to encounter strong resistance were combined with more popular ones in order to increase overall public support (also see Banister 2003). In the end, they highlight the role of policy-packaging and suggest strategies to better manage the barriers associated with a lack of public support and political resistance. These strategies include combining sticks and carrots, implementing trials to create legitimacy and support, and using communication strategically. Similarly, Hysing and Isaksson (2015) compare political stakeholder and mass public support for congestion charges in case studies of Stockholm and Gothenburg. In this case, pricing proposals are met with a lot of opposition even though this measure is widely regarded by transportation experts as an efficient demand side intervention (Huber, Wicki, and Bernauer 2019; Schuitema, Steg, and Forward 2010; Schuitema, Steg, and Rothengatter 2010). They eventually find that consistency of objectives in policy-packages, communication, and marketing efforts are key to ensuring public support for a policy-package.

On the other hand, in contrast to what one might assume, a survey among Swedish car owners in which values and policy-specific beliefs were modelled to predict support for different primary measures, individually and as packages, suggests that policy-packaging consisting of push and pull measures decreases support for the overall proposal (Eriksson, Garvill, and Nordlund 2008). In other words, while car owners support pull measures, they focus on the push factors in packages, thus decreasing the overall support (Eriksson, Garvill, and Nordlund 2008, 1126). Despite contrasting findings, their study also reveals that combining measures to improve public transportation or subsidies with higher taxes on fossil fuels 
tends to increase support for the overall package by 0.63 and 1.32 on a seven point scale respectively (Eriksson, Garvill, and Nordlund 2008, 1123). This result is in line with findings by Schade and Schlag (2003), who also observe low support levels for policy-packages consisting of pull and push factors, even if the support for a package is higher than for the individual push measure.

Furthermore, additional research reveals that earmarking revenues may increase public support when a tax is included. Through a stated preference method, Bristow et al. (2010) show that support for carbon trading and carbon tax schemes can increase depending on earmarking. Likewise, a choice experiment on fuel taxation in Norway shows that, without earmarking, a majority of voters favour fuel tax reductions, whereas earmarking revenues towards environmental measures leads to a significant upsurge in support for fuel tax increases (Sælen and Kallbekken 2011). Kallbekken and Aasen (2010) provide similar evidence from a focus group study in Norway, finding strong preferences to earmark revenues for environmental purposes.

Other studies, however, suggest that trials can help in increasing public support for policies. Cherry et al. (2014) examine the effect of trial periods on public support for two tax schemes by constructing an experimental market. While they find significant opposition to taxes, their results show that trial runs can overcome initial tax aversion. Moreover, trial periods can also mitigate initial biases in preferences of alternative tax schemes (Cherry, Kallbekken, and Kroll 2014).

In summary, primarily based on qualitative case studies, the existing literature has focused mainly on the effects of policy-packaging on problem solving effectiveness. Studies on how policy-packaging might affect mass public support and political feasibility is scarce. The research by Eriksson et al. (2008) is thus a rare case. Additionally,, extremely few studies on policy-packaging and its effect on mass public support for policies use an experimental approach, even though this approach can help in overcoming causal inference problems plaguing research based on conventional survey data. In addressing this research gap, we use a state-of-the-art choice experiment embedded in a nationally representative survey in Switzerland. In this choice experiment, we study participants with varying combinations of different primary (command-andcontrol and market-based) and ancillary measures. We thus build upon and expand on the study by 
Eriksson et al (2008) who combine one specific push measure (taxes) with one of two specific pull measures (subsidies for renewable fuel or improved public transportation).

\section{Arguments}

Our main argument is that policy-packaging is likely to affect public support levels positively. Our focus is on four primary and three ancillary measures in particular. We consider (i) stricter energy labels, (ii) registration ban on high emission cars, (iii) road pricing, and (iv) emission dependent car tax as primary measures, as well as (v) accompanying information campaigns, (vi) test phases for policies, and (vii) experts involvement as ancillary. The selection of these seven measures was validated based on several expert interviews (for details, see Table A11 in the supplementary information (SI)). For a brief description of each measure, refer to the study design section below. Everything included, we examine how these measures affect support for the respective policy-package.

Primary measures aim directly at the main policy target, namely reducing vehicle emissions and promoting electric cars. Ancillary measures aim at increasing public support by reducing potentially adverse effects of primary measures. For example, an accompanying information campaign may have the effect of increasing support for primary measures by informing citizens about the rationale behind the primary measure, which in turn could mitigate misperceptions and prejudices. In what follows, we will discuss potential effects of primary and ancillary measures on public support, focusing on the direct effects of primary (H1) and ancillary $(\mathrm{H} 2)$ measures as well as their interaction $(\mathrm{H} 3)$.

Public support for policy-packages is likely to depend on the included (primary) policy measures. We categorise primary measures into two groups: command-and-control regulations and market-based instruments (also see Stadelmann-Steffen 2011; Vedung 1998). While command-and-control measures regulate behaviour directly (i.e. emission standards for vehicles, technology standards, or bans of certain products), market-based instruments (i.e. car taxes and road pricing schemes) use price mechanisms to influence the behaviour of actors (Böcher 2012; Dargusch and Griffiths 2008). Although many, if not most, environmental economists regard market-based instruments as the most efficient approach (Dargusch and 
Griffiths 2008; Hahn and Stavins 1992), various studies show that their de facto use is limited due to insufficient public support (Cherry, Kallbekken, and Kroll 2012; Stadelmann-Steffen 2011).

On the other hand, command-and-control instruments are more common, not least because they tend to garner more support from the mass public (Felder and Schleiniger 2002; Kirchgässner and Schneider 2003). As Stadelmann-Steffen (2011) shows, voters usually prefer command-and-control policies over marketbased instruments (also see Kirchgässner and Schneider 2003). Cherry et al. $(2012,90)$ offer a similar conclusion, noting that voters tend to contest market-based instruments. Overall, command-and-control measures consolidate more support because their costs appear less visible as opposed to market-based instruments, which intrinsically generate monetized information about policy effects (Schulz 2001; Stadelmann-Steffen 2011). Consequently, voters tend to underestimate the costs of command-and-control instruments as a result (Kirchgässner and Schneider 2003; Pleger 2017).

Based on interviews with transportation experts (see Table A11 in the SI for more information), we concentrate on two market-based and two command-and-control measures in the area of transportation to test these expectations. While we focus on registration bans on high emission cars and on stricter energy labels regarding car emissions for command-and-control measures, we centre on road pricing and an emission dependent car tax for market-based instruments. Further details are provided in the study design section below. In this way, Hypothesis 1 summarizes the empirical implications of the above argument.

H1: Primary command-and-control measures receive more public support than primary marketbased instruments.

When incorporating other measures to a policy-package, policy-makers must consider the relationship between those measures as to avoid contradictions and enhance synergistic relations (Givoni et al. 2013). Therefore, in this paper, we specifically aim our attention at how the inclusion of ancillary measures affects public support directly and how they interact with primary measures. To do so, we select three possible ancillary measures to be included to our policy-packages: accompanying information campaigns, test phase and evaluation, and expert involvement. An accompanying information campaign, as 
conceptualized in our study, explains the content of a given policy-package and responds to possible public concerns. Thereby informing citizens, which may increase public support for the policy-package. Including a test phase in a policy-package indicates that the package will be re-assessed after the testingperiod to see whether it achieved its goal. The subsequent assessment will then determine whether the package is permanently implemented or not, and finally, we will propose to include experts in the implementation and design phase of the package expecting this could increase public support for the package.

There are several reasons why including these ancillary measures may enhance public support directly. Departing from the supplementing information campaign, informing citizens tends to increase awareness of the policy challenge. It may as well help instil trust and lead to more public support by reducing loss aversion (Milkman et al. 2012). This mechanism might already occur when announcing an accompanying campaign, as citizens prefer policies that actively inform about their implementation and thus facilitate their monitoring process. To illustrate this argument an example of road pricing is applicable. The cities of Manchester and Edinburgh were unable to implement a pricing scheme because the policy-packages they developed were unacceptable to the public. At the same time, a similar policy was successfully implemented in London. Even though existing studies on these cases are non-experimental and may not sufficiently control for varying boundary conditions, the public address of policy-making appears to have caused the diverging results. Unlike in Manchester and Edinburg, the process in London focussed on feasibility, proving to be critical in the implementation of the policy (Banister 2003). More specifically, some policies in the London package aimed at increasing public support by providing additional information on the consequences of the package at hand, rather than aiming at the overall policy goal of the package (Givoni 2014; Schuitema, Steg, and Forward 2010). However, it is important to note that with the approach in this paper, respondents are not exposed to the campaign directly, but rather the idea of its existence and thus only covers a general desire to potentially receive monitoring information about the respective policy implementation.

Aside from the expected positive effects of information campaigns, however, test phases can help the public better understand policy functioning. Existing literature suggests that citizens are more supportive 
of policies once they are in place, compared to those that only proposed (Schuitema, Steg, and Forward 2010). This is explained as test phases generate more information that may help reduce loss aversion and evidence-based evaluation of a trial policy allows policy-makers to either revise or abandon the policy if the results are not as desired (Milkman et al. 2012; Schuitema, Steg, and Forward 2010). Additionally, we expect that expert inclusion in the policy-making process will help increase policy effectiveness, and strengthening the policy's legitimacy as a result. To the extent citizens acknowledge such expertise and its implications, we should expect that adding expert involvement to policy-packages induces higher public support levels. Altogether, Hypotheses 2 reflects all the expected effects of the three ancillary measures we consider. ${ }^{\text {iv }}$

H2: The inclusion of ancillary measures in a policy-package tends to increase public support for the package.

As outlined above, the expected positive effect of ancillary measures in a policy-package can mitigate the potentially negative effects of primary measures on policy-package public support directly or indirectly. Therefore, we argue that policy-packaging may also create positive synergies between instruments (Gunningham and Sinclair 1999, 2017; Howlett 2011; Howlett, How, and del Rio 2015; Howlett and Rayner 2013). Empirically speaking, interactions between primary and ancillary measures would indicate that certain combinations are more popular than others or that the positive effect of including ancillary measures is not the same for all primary measures. Thorpe (2000) suggests to reflect on combinations of specific primary and ancillary measures, and he argues that well-matched combinations could increase public support for the whole package. For instance, if policy-makers seek to reduce the use of fossil-fuelled cars by providing citizens with practical alternatives to their current mode of transportation, such as improved public transportation, a potential backlash could be prevented. With such a package, citizens would not perceive a decrease in utility as large as with a simple tax increase on fossil fuels (Cherry, Kallbekken, and Kroll 2012). Similarly, Stadelmann-Steffen (2011) provides another example. She claims the costs of traditional command-and-control policies are less visible compared to market-based instruments (also see Schulz 2001). Therefore, informing individuals, via an information campaign, regarding market-based instruments might have a larger marginal positive effect on citizens' support when 
compared to adding an information campaign on command-and-control measures. Thus, as loss aversion by individuals tends to be tackled more directly, we hypothesize that ancillary measures are likely to have a stronger support increasing effect with regard to market-based instruments. In other words, we expect that individuals tend to evaluate market-based instruments more negatively as they systematically underestimate costs of command-and-control measures. Therefore, we expect a higher marginal effect of the inclusion of ancillary measures on public support for the policy-package if the latter includes marketbased instruments. Hypothesis 3 summarizes this hypothesized effect accordingly.

H3: Including ancillary measures in a policy-package increases public support for the package. This support increasing effect is stronger with respect to market-based instruments than with respect to command-and-control instruments.

\section{Empirical Study Design}

In this section, we begin by briefly describing our empirical case (4.1) to later describe the sampling strategy (4.2), the survey (4.3), and the experimental design (4.4).

\subsection{Empirical Case: Transportation Policy in Switzerland}

Our empirical analysis focuses on transportation policy in Switzerland for the following reasons: First, transportation policy in this country (as in many others) is highly contested (Sager 2007). In contrast to policies aimed at expanding capacity for private (and public) transport, those that limit and/or increase costs of motorised private transport are highly controversial and tend to attract strong opposition. While building new roads is an example for the former (Thalmann 2004), strong opposition to road pricing and fuel taxes are examples of the latter (Zaslawski 2017). As a result of these challenges, transportation is the only sector where Switzerland (as several other high income countries) has failed to achieve a significant reduction of greenhouse gas emissions thus far. As a matter of fact, in terms of $\mathrm{CO}_{2}$ emissions of newly registered cars, Switzerland performs worst among Western European countries (European Environment Agency 2017).

Moreover, the Swiss system of direct democracy makes major policy changes subject to approval by citizens through a national vote, where the voting population acts as a formal veto-player (Stadelmann- 
Steffen 2011). Direct democracy in Switzerland has two different instruments of direct political participation. First, proposals for constitutional amendments (also called 'popular initiatives') require initial support from $100^{\prime} 000$ eligible Swiss voters to be brought into a national vote. Additionally, with the referenda, the population has final sovereignty over newly introduced laws by the national parliament (Linder 2012). These forms of direct-democratic participation rights are actively exercised by the Swiss population. Between 1971 and 2018, there were a total of 402 national direct-democratic ballots on the national level $^{v}$ (Federal Statistical Office 2018; Vatter 2016). Generally, this indicates that each year, the population votes on about eight democratic ballots, half of which are based on Parliament's proposals and the other half on popular initiatives (Federal Statistical Office 2018; Linder 2012). In political reality, directdemocratic mechanisms tend to create a status quo bias (Brunetti and Straubhaar 1996; Tsebelis 2002) and make government intervention more challenging (Freitag, Vatter, and Müller 2003; Sager, Ingold, and Balthasar 2017). In any case, mass public policy preferences are crucial in this type of system. Our choice experiments can thus be carried out in a context where citizens are in fact likely to vote on the issues we are asking them about (Jaensirisak, Wardman, and May 2005; Sørensen et al. 2014).

\subsection{Sampling}

Our conjoint experiment was embedded in a non-probability online survey (Toepoel 2015) designed by the authors and fielded by IPSOS between December $8^{\text {th }}$ and $21^{\text {st }} 2017(N=2,034)$. The survey was carried out in all 26 cantons of Switzerland in three languages (French, German, and Italian), was constructed on quotabased sampling, and used three interlocked quota: a) gender (2-groups), b) age-group (6-groups), and c) region (7-groups). In other words, our sample is representative for the population of Switzerland according to these quotas. ${ }^{\text {vi }}$ Additionally, a parallel quota for the living situation of participants was applied. This quota distinguishes between urban agglomeration and rural living areas.

\subsection{Survey}

The survey starts with questions on standard demographics such as age, gender, and education. The subsequent section of the survey asks participants about their mobility behaviour. To assess potential policy framing effects, participants were then randomly assigned to two different frames: a) promotion of electric vehicles ( $E V$ frame) and b) reduction of emissions from cars (emission reduction frame). We employ 
these two policy frames because transportation policy usually focuses on one or the other. In other words, the two frames present the same policy proposals to survey participants, but frame them differently. We have no particular theory on how policy-making in the context of one or the other frame influences the treatment effects of interest here. We are interested, however, in exploring whether the general policyframe could moderate treatment effects in some way or whether our findings hold across different frames. Balancing vii ascertains that the quota is met in both framing groups. Afterwards, survey participants are introduced to the concept of a policy-package and its various contents. Attributes (i.e. contents of the policy-package) are introduced to participants before the conjoint experiment starts. To establish internal validity, we described all attributes in the experiment beforehand (Carson and Hanemann 2005, 898), and later, after the conjoint experiment, the survey concluded with some final questions (i.e. income).

\section{[Table 1 about here]}

\subsection{Experiment}

To assess the theoretical arguments set forth above, we use a conjoint experiment. Conjoint experiments are particularly useful for studying causal effects of multiple variables in rather complex decision-making processes (Hainmueller, Hopkins, and Yamamoto 2014; Rienstra, Rietveld, and Verhoef 1999). In our setting, study participants are asked to express their preferences concerning policy-packages consisting of different policy measures (we call them attributes) whose characteristics are randomly assigned.

At the beginning of our conjoint experiment, we provide basic information on each of the included measures (attributes/contents of a policy-package) and continue with instructions for completing the conjoint experiment. The key part of the conjoint experiment consists of tables showing features (attributes and their possible characteristics) of different policy-packages. These are shown in Table 1. We confront study participants with policy-packages including nine attributes (see Table A12 in the SI for the exact wording of attributes and their expressions). Specifically, policy-packages in our study consist of three different types of instruments: primary measures, ancillary measures, and other aspects of policy-design.

First, policy-packages encompass different primary measures (in our case: stricter energy label, registration ban on high emission cars, road pricing, and emission dependent car tax). viii Second, we included three 
ancillary measures (in our case information campaign, test phase, and expert involvement). Third, we include other aspects of policy-design which might be related to public acceptability. We also include earmarking the revenues from road pricing and the emission dependent car tax. The earmarking dimension identifies how policy-package revenues will be repurposed. The car tax is designed in a way that it is always present either as the status quo where Swiss cantons (the main subnational units) have different regulations or as a nationally harmonised car tax. Furthermore, we included five different years when implementation would start. We generally anticipate that respondents prefer a later implementation of far-reaching (costly) policies, as the imposed costs are more distant and individuals have more time to adapt. This is in line with standard assumptions about discounting in economic literature.

The included attributes are listed and described in Table 1, where all attributes in every conjoint table are included, nonetheless with varying characteristics of each attribute. In other words, all respondents consistently see all attributes and their assigned attribute characteristics explicitly state whether or not this attribute is part of the policy-package. ${ }^{\text {ix }}$

[Figure 1 about here]

After respondents have familiarised themselves with the nine attributes and their possible characteristics, each respondent is asked to compare sets of two proposals for a policy-package shown side-by-side. Study participants are confronted with five pairs of differing policy-packages and are asked to decide which proposal they prefer within each pair. Both events appear in a forced-choice mode and on a seven point rating scale (see Figure 1 for an example). The values (attribute characteristics) on each attribute are inserted randomly into the tables. Since all attribute characteristics are randomly assigned, we can estimate the average marginal component effect (Hainmueller, Hopkins, and Yamamoto 2014; Louviere, Hensher, and Swait 2000). To avoid ordering effects, however, the order of the attributes is randomly assigned for each participant initially and then held constant per participant for the following four choice tasks to avoid cognitive overload. After being confronted with a pair of proposals, respondents are asked to express their preference for one or the other (binary choice task; "If you had to decide: Which of the two proposals would you choose?") and then to rate each proposal on a scale ranging from 1 to 7 ("How much do you agree or disagree with proposal $1 / 2$ ?"). The unit of observation in the resulting dataset is 
defined by the response variable which is the response to each proposal. Consequently, two observations for each choice task are generated, with a total of 10 observations per participant since there are five choice tasks. For a sample of 2,034 participants, the number of observations is thus 20,340 .

As the included policy measures are rather information-heavy, it is important to address the issue of a potential masking-satisficing trade-off. Indeed, research on survey taking indicates that more onerous survey tasks potentially leads to satisficing effects, which means that respondents adapt their response behaviour by using cognitive and time-saving shortcuts potentially degrading response quality (Krosnick 1999). Thus, it is possible that empirically observable quantities diverge from those of theoretical interest (Bansak et al. 2019). However, Bansak et al. (2019) show that there is rather limited increases in survey satisficing by testing whether up to 35 attributes can be included into a choice task. Results indicate that there is only a modest decline in the estimated causal effects of interest as the number of filler attributes rises and thus conjoint surveys can reliably recover estimates that are sensible and significant both statistically and substantively (Bansak et al. 2019). Still, it is important to keep in mind that the rather complex conjoint design might affect the outcome. Thus, we include analysis that tests for both satisficing effects regarding the number of rounds (Figures A9 and A10) as well as the number of attributes present in the conjoint task (Table A9).

The conjoint experiment is presented to study participants in one of two ways (policy frames). One is a pull frame (enabler), in which policies encourage desired travel behaviour, while the other is a push frame (deterrent), in which policies discourage non-desired behaviour (Piatkowski, Marshall, and Krizek 2017; Steg, Dreijerink, and Abrahamse 2006; Stradling, Meadows, and Beatty 2000; Thorpe, Hills, and Jaensirisak 2000). In our specific case, the pull frame presents policy-packages designed to promote electric vehicles (EVs), while the push frame presents policy-packages to reduce emissions from transportation. The EV promotion frame in our experiment portrays electric vehicles as a substitute for conventional cars. The other frame, a reduction of high-emitting cars, is based on the presumption that reduced emissions are necessary to mitigate climate change.

The data analysis is based on linear mixed effects regressions to estimate the average marginal component effect (AMCE) (R Core Team 2015). ${ }^{\times}$We use individuals as tier 2 group, which is in line with a suggestion by 
Hainmueller et al. (2014) that allows us to estimate the effects of the EV and the emission reduction frames and other covariates. We control for a variety of well-known potential determinants of public support for transportation policies, such as car usage (Kallbekken, Garcia, and Korneliussen 2013; Lubell, Zahran, and Vedlitz 2007), age, gender, income, and education (Kim et al. 2013).

\section{Empirical Results}

In this section, we present the main empirical findings from the conjoint experiment which is designed to test the three hypotheses previously outlined. Section 5.1 examines the direct effects of primary command-and-control and primary market-based measures as well as ancillary measures on public support ( $\mathrm{H} 1$ and $\mathrm{H} 2$ ). Section 5.2 looks at potential interaction effects between the different attributes of a policypackage.

\subsection{Direct effects of policy-package attributes}

Figure 2 shows the AMCEs of all attribute values included in the policy-package for both the choice and the rating scale (see Table A10). ${ }^{\text {i }}$ Regarding the two market-based instruments (road pricing and car tax), road pricing has by far the most negative and significant effect of all primary measures. Packages including road pricing as a measure were significantly less likely to be selected in the choice task and rated lower in the seven-point Likert scale capturing policy support. The emission-dependent car tax has a significant and positive effect on the likelihood of selecting the policy-package in the choice task but not in the rating of the individual packages.

\section{[Figure 2 about here]}

Both command-and-control measures were evaluated positively in both the choice and rating scales. The inclusion of stricter energy labels in a policy-package on average has a positive effect on public support. To implement such a label compared to the baseline of not implementing it increases the likelihood of supporting the proposal by $3 \%$ in the choice task. Including a registration ban on high emission cars leads to significantly higher support for the policy-package. This finding is somewhat surprising since bans are presumably highly intrusive. Nevertheless, this finding lends support for $\mathrm{H} 1$, indicating that the public prefers regulatory instruments over market-based solutions. These results are in line with findings in other 
studies (see e.g. Huber, Wicki, and Bernauer 2019) and suggest that introducing a hard (regulatory) policy measure may engender a technological change towards more sustainable engines in transportation. These findings support our expectations stated in $\mathrm{H} 1$.

The results for the three ancillary measures support our theoretical expectations stated in $\mathrm{H} 2$. Ancillary measures in a policy-package increase support for the whole package. Both the inclusion of an accompanying information campaign as well as a test phase with a subsequent evaluation increase support, both on the choice and the rating scale. The inclusion of experts in the implementation process also exhibits a positive effect, though this effect reaches conventional significance levels only in the choice task. A new finding, however, is the discovery that announcing an accompanying information campaign increases public support ahead of the implementation. This might be explained as individuals tend to favour policies which provide information in advance.

Earmarking of revenues from policy-intervention, in general, does not appear to play an important role. While allocating revenues towards the general government budget attracts more opposition, when compared to the baseline measure, neither of the other earmarking measures seems to have an impact on support for a policy-package. Moreover, the implementation date has only a minor effect with somewhat more support for earlier rather than later implementation, which is surprising given people's tendency to discount the future costs of policy interventions. Still, the effect of implementation date is relatively small and is generally statistically insignificant.

Regarding the control variables, we observe that older participants rated policy proposals slightly lower than younger ones. The same holds for male and female study, as well as individuals with primary education and individuals with tertiary education. Not surprisingly, however, the number of days a person uses a car in a week has the strongest effect (see Table A9). This effect is highly significant in all our models and it indicates that, on average, individuals who rely on a car rated any policy-packages lower. Interestingly, we did not find a significant difference between the two policy frames, indicating that the effects of policy-packaging and the different primary and ancillary measures do not depend on the framing of the policy goal. 
Figure 3 shows the predicted probabilities of selecting a policy-package depending on the number and types of ancillary measures that are part of the policy-packaging and distinguished by whether the four primary measures were present in the package or not. We therefore estimated models with two-way interaction effects (each primary measure with each ancillary measures), three-way interaction effects (packages with the primary and a maximum of two ancillary instruments), and, finally, all possible combinations of a specific primary measure and ancillary measures for both the rating and the choice scale ${ }^{x i i}$. The colours indicate the number of ancillary measures in the prediction, whereas the shape indicates which ancillary measures where part of the respective package. Policy-packages that exclude any ancillary measures receive less support and do not gain a majority in the predicted support.

[Figure 3 about here]

Starting with command-and-control measures (left group of predictions, Figure 3), including an accompanying campaign achieves more than $50 \%$ of the vote share ${ }^{\text {xii }}$ for car taxes, whereas the other two ancillary measures do not lift support above $50 \%$ (see dot dashed/orange ranges in Figure 3). Similarly, including two ancillary measures (see dashed/violet ranges in Figure 3 ) shifts public support above 50\% for both command-and-control measures. For stricter energy labels, this positive shift is the case when including experts and test phases. Including all three ancillary measures further increases support by almost 10 percentage points.

Looking at market-based instruments, the inclusion of one ancillary measure tends to increase support. However, these increases are not statistically significant and never exceed $50 \%$. For road pricing, however, support is always significantly lower than $50 \%$. Including two ancillary measures lifts support above $50 \%$ for two out of three cases for the car tax. The change is also significant and support is indistinguishable from $50 \%$ for the two packages including test-phases as ancillary measure. When all three ancillary measures are added to a policy-package, both packages including emission dependent car taxes or road pricing receive substantially more support and car taxes receive more than $50 \%$ support as well. Altogether, we find similar patterns regarding the predicted rating of policy-packages as shown in Figure A4. ${ }^{\text {xiv }}$ These 
results provide further support for $\mathrm{H} 2$ and indicate that the inclusion of ancillary measures does have a substantial positive effect on support for a package.

Figure $\mathrm{A} 1$ and Figure $\mathrm{A} 2$ summarise the interaction effects between the number of primary and ancillary measures to control for potential satisficing effects. For the former, no significant positive effect can be observed when including additional primary measures into the package. Thus, there appears to be no evidence of a possible count effect for the number of policies included into the policy-package. This is also supported by the results displayed in Figure A7 and Figure A8, where the predicted support for policypackages including different numbers of primary measures is displayed. Thereby, only packages which road pricing appear to be consistently less supported, whereas no significant effect is observed regarding the amount of primary measures included.

Figure 4 compares how the number of ancillary measures included in a package performs across the different primary measures. ${ }^{\mathrm{x}}$ We standardised support for all primary measures on zero to identify differences in additional support when including ancillary measures. We expected the effect of ancillary measures to be stronger for market-based instrument compared to command-and-control measures. Yet, the results do not indicate a significant difference between the four primary measures. If anything, the effect is strongest for command-and-control measures in the sense of stricter energy labels in the choice task and for the market-based instruments in the form of an emission dependent car tax in the rating scale. These differences are nonetheless statistically insignificant and thus $\mathrm{H} 3$ is not supported.

\section{[Figure 4 about here]}

We also tested how the number of ancillary measures and the number of primary measures included in a package affect support. In all choice models presented in Table A9 in the SI, the estimates for both the number of primary measures and the number of ancillary measures are positive, indicating that the more measures included the higher the support for the package. While this effect is significant at the $10 \%$ level for ancillary measures in all rating scale models, we do not find a significant positive effect of the number of primary measures on the rating score. Therefore, we do not find any substantive empirical evidence for positive (or negative) interaction effects (also see Table A10 in the SI). 


\section{Discussion}

In this paper we examine whether assembling different policy measures into policy-packages increases public policy support and thus enhances the political feasibility of policy interventions. In our conceptualization, such packages can include primary and ancillary measures. While the former aim directly at a given policy goal, the latter are meant to help offset or overcome potentially adverse effects of primary measures on policy support. We argue that primary command-and-control measures tend to garner more public support relative to primary market-based measures. This claim aligns with previous literature arguing that market-based policy instruments tend to be disliked by the public. Moreover, we hypothesize that ancillary measures tend to increase public support directly as well as indirectly, where the latter mitigates potential negative effects of primary measures. In other words, we conjecture that ancillary measures could help overcome political feasibility obstacles when it comes to adopting and implementing far-reaching and, thus, costly policies. Focusing on strategies against vehicle emissions in Switzerland, where policies are highly controversial and citizens are incessantly requested to voice their opinions in the ballots, we tested our theoretical arguments with data from an original and nationally representative survey experiment of 2,034 citizens.

The empirical findings provide robust support for two out of three theoretical expectations. First, command-and-control measures tend to garner more support, compared to market-based measures. Most notably, public support for a ban on vehicles with high emissions is significantly stronger, compared to road pricing and car taxes more strongly scaled on emissions. Second, policy-packages including ancillary measures receive significantly more support. Third, our expectation that ancillary measures can reduce loss aversion in the case of market-based instruments more than in the case of command-and-control policies is not supported by our empirical analysis.

The policy-relevance of our analysis derives from the fact that it can help inform policy-makers on whether or not to design policy-interventions in the form of larger policy-packages, and what the positive and negative implications of specific policy measures in such packages could be for political feasibility. One key finding is that ancillary measures can aid in enhancing political feasibility, particularly in the form of information campaigns, test phases, and involvement of experts. Another key finding is that even highly 
intrusive command-and-control measures, such as bans on cars with high emissions, are more popular than market-based instruments (i.e. road pricing). This finding is broadly in line with some previous studies (Hansla et al. 2017; Jaensirisak, Wardman, and May 2005; Vonk et al. 2014).

In conclusion, while this paper provides valuable insights in the implementation of contested policies, it becomes imperative to identify the limitations of our study and suggest avenues for further research. The argumentation in this paper followed the motivation to identify ancillary measures that can ameliorate adverse public support. Nevertheless, this argument also builds on the implicit assumption that policymakers have enough foresight and strategic reasoning to design policy-packages which only consider ancillary measures with positive impacts, and as recent research shows, this assumption neither holds for politicians (Sheffer et al. 2018) nor bureaucrats (Bellé, Cantarelli, and Belardinelli 2018). Therefore, to account for reality, further research could evaluate how public support for policy-packages is influenced when popular and unpopular ancillary measures are included. Additionally, the treatment specification used in this paper is rather general and does thus not allow to identify what specifically drives the observed effects. Regarding the information campaign, this is an important point to consider as results presented in this paper appear to only reflect the general desire of citizens to receive information about the respective policy.

Furthermore, the choice of policy instruments included into the policy-packages is confounded with the case of Switzerland, as the inclusion of information-heavy policies was only possible when including specific issues that were recently discussed and were externally valid. This realistic approach leads to some limitations of the generalizability one can make about the specific policy-package effects, as it is rather case specific. With this in mind, further research in different cases should be conducted as to develop a comparative scope regarding the specific mechanisms behind the effect of policy-packaging on public support. In addition, it is necessary to mention the research design at hand cannot fully control for potential satisficing effects as all respondents were presented the same conjoint task. Specifically, it is not possible to fully control for potential count-effects as a counterfactual of a conjoint design with more or less attributes is missing. To test for this, future research could potentially test how the number of measures included into a policy-package affects the respective effects (see, for example, Fesenfeld 2019). 
Additionally, while conjoint experiments are methodologically rigorous and allow for quite realistic choice scenarios in situations where multiple policy-attributes matter simultaneously, they also have some limitations. Our approach allows us to obtain robust estimates of policy-design feature effects on public support for transportation policies, however, our results also yield rough estimations of the extent to which citizens in Switzerland are likely to react to future policy interventions. Therefore, absolute support levels observed in our study need to be treated with caution, as the concrete design of a policy proposal might fundamentally differ in reality and public discussions and campaigns for/against such a proposal may alter citizens' assessment of specific measures or the overall package.

Moreover, we opted for a design where all attributes always appear in the policy-package and may take on characteristics that range from no measure of the particular kind to introduction of such a measure. Future research could examine whether our main findings uphold when adding or dropping such particular attributes from the package (i.e. not showing them in the conjoint table altogether). As to which presentation is better, one that drops the attributes, or one that includes all (as done in this paper) remains subject to debate. Additional options for further research include the examination of policy-packaging effects in other policy-areas and other countries as well. All being said, we hope the research presented here lays the foundation for a larger research effort centring on how policy-packaging affects public policy support and, thus, enhance the political feasibility of far-reaching policy interventions desperately needed to address the challenges of today. 
'The literature offers various definitions of social acceptance (Dermont et al. 2017). Policy acceptability refers to mass public attitudes before the implementation of a policy. Policy acceptance refers to mass public attitudes after a policy's implementation (Schade and Schlag 2003; Schuitema, Steg, and Rothengatter 2010). In any event, in most cases, to be feasible a policy needs to be supported by a majority of citizens - especially in the Swiss context of direct democracy, on which we will focus empirically. We follow Jaensirisak et al. (2005) and empirically capture citizens' willingness to vote for a policy proposal. This reflects the understanding that public support is essential for enacting and implementing costly policies (Jaensirisak, Wardman, and May 2005). We also follow the argumentation by Dermont et al. (2017) and use the term support as a de facto decision at a stage where a policy solution is to be adopted.

ii At the time of writing (20. September 2018), 8 billion Swiss Francs equal 7.08 billion Euros and 8.31 billion US Dollars.

iii See Ring and Barton (2015) for a literature review on policy mixes, a closely related concept.

iv It is important to note that we only include ancillary measures that are anticipated to increase public support. This is due to the strong policy relevance of our study and its aim to understand what policy-makers could do to boost implementability. However, in theory, not all ancillary measures need to foster public support. For example, specific ancillary exemptions from odd-even rules is India did not provide additional support but rather backfired, as nonexempt individuals felt treated unfairly (Bernauer, Prakash, and Beiser-McGrath 2018).

$\checkmark$ There are further democratic ballots on the cantonal and municipal levels, which are used and applied quite differently among the different governmental entities.

vi Please note that the frames function as a fourth interlocked quota, which ensures that the distribution of age, gender, and region is similar in each frame.

vii Balancing means equal quota distribution in both treatment groups in order to avoid imbalances due to chance.

viii We designed the conjoint experiment so that either road pricing or the car tax is present. Thereby, we ensure that each proposal includes at least one primary measure. This is necessary, as some form of revenue is required due to the inclusion of earmarking.

ix We follow an intention to treat logic in the analysis of our experimental design. While we do not include a comprehension check, the findings are robust to excluding individuals who took less than half the median response time based on the assumption that people who finished the survey faster were less attentive and may have missed more information.

${ }^{x}$ All steps from recoding to the analyses were done in R. We used the following packages to recode, for the analyses, and the output: cjoint (Hainmueller, Hopkins, and Yamamoto 2014), data.table (Dowle and Srinivasan 2017), dyplr (Wickham and Grolemund 2017), nFactors (Raîche et al. 2013), ggplot2 (Wickham 2009), Ime4 (Bates et al. 2015), effects (Fox 2003; Fox and Hong 2009), ggthemes (Arnold 2017), influence.ME (Nieuwenhuis, te Grotenhuis, and Pelzer 2012), tidyr (Wickham 2016), forcats (Wickham 2017) and texreg (Leifeld 2013).

${ }^{x i}$ We also ran the rating task including control variables as a robustness check. The results indicate that including controls does not at all affect the estimated AMCEs, which had to be expected as the random assignment should by expectation wash off any potential covariance with the treatment variables. Additionally, we controlled for learning effects over the five iterations of choice situations the respondents were confronted with. These results are shown in Figure A9 for the choice task and Figure A10 for the rating task. The results do not indicate significant results that any learning effect took place.

xii Table A1, Table A2, Table A3, Table A4, Table A5, Table A6, Table A7, Table A8, and Table A9 in the SI summarise the regression results for choice and rating scales.

xiii Meaning the predicted likelihood of choosing a policy-package in the conjoint experiment.

xiv Also see Figure A5 for the choice task and Figure A6 for the rating task for margins set to zero for every primary measure.

${ }^{x v}$ Figure $A 3$ in the appendix shows the predicted rating scores for the four primary measures included in different policy-packages separately. 


\section{Bibliography}

Anderson, Brilé, Tobias Böhmelt, and Hugh Ward. 2017. "Public Opinion and Environmental Policy Output: A Cross-National Analysis of Energy Policies in Europe." Environmental Research Letters 12(11): 114011. http://stacks.iop.org/1748-9326/12/i=11/a=114011.

Andersson, David, and Jonas Nässén. 2016. "The Gothenburg Congestion Charge Scheme: A Pre-post Analysis of Commuting Behavior and Travel Satisfaction." Journal of Transport Geography 52: 82-89. http://www.sciencedirect.com/science/article/pii/S0966692316000430.

Arnold, J B. 2017. "Ggthemes: Extra Themes, Scales and Geoms for 'ggplot2."' R package version 3.4. 0.

Balmer, Ueli. 2005. "The Window of Opportunity: How the Obstacles to the Introduction of the Swiss Heavy Goods Vehicle Fee Have Been Overcome." OECD Papers 5(5): 1-39. https://ideas.repec.org/a/oec/packaa/5lgmkvgbcjop.html.

Bamberg, Sebastian, and Daniel Rölle. 2003. "Determinants of People's Acceptability of Pricing Measures: Replication and Extension of a Causal Model." In Acceptability of Transport Pricing Strategies, eds. Jens Schade and Bernhard Schlag. Oxford, UK: Elsevier Science, 235-48.

Banister, David. 2003. "Critical Pragmatism and Congestion Charging in London." International Social Science Journal 55(176): 249-64. https://doi.org/10.1111/j.1468-2451.2003.05502006.x.

Bansak, Kirk, Jens Hainmueller, Daniel J. Hopkins, and Teppei Yamamoto. 2019. "Beyond the Breaking Point? Survey Satisficing in Conjoint Experiments." Political Science Research and Methods forthcomin: 1-19. https://doi.org/10.1017/psrm.2019.13.

Barton, David N et al. 2017. "Payments for Ecosystem Services as a Policy Mix: Demonstrating the Institutional Analysis and Development Framework on Conservation Policy Instruments." Environmental Policy and Governance 27(5): 404-21. https://onlinelibrary.wiley.com/doi/abs/10.1002/eet.1769.

Bates, Douglas, Martin Mächler, Ben Bolker, and Steve Walker. 2015. “Fitting Linear Mixed-Effects Models Using Ime4." Journal of Statistical Software 67(1). http://www.jstatsoft.org/v67/i01/.

Bellé, Nicola, Paola Cantarelli, and Paolo Belardinelli. 2018. "Prospect Theory Goes Public: Experimental Evidence on Cognitive Biases in Public Policy and Management Decisions." Public Administration Review 78(6): 828-40. https://doi.org/10.1111/puar.12960.

Bemelmans-Videc, Marie-Louise, Ray C Rist, and Evert Oskar Vedung. 2011. 1 Carrots, Sticks, and Sermons: Policy Instruments and Their Evaluation. Transaction Publishers.

Bernauer, Thomas, Aseem Prakash, and Liam F Beiser-McGrath. 2018. "Do Exemptions Undermine Environmental Policy Support? An Experimental Stress Test on the Odd-Even Road Space Rationing Policy in India." Regulation \& Governance 0(0). https://doi.org/10.1111/rego.12225.

Böcher, Michael. 2012. "A Theoretical Framework for Explaining the Choice of Instruments in Environmental Policy." Forest Policy and Economics 16: 14-22. https://doi.org/10.1016/j.forpol.2011.03.012.

Bontoux, Laurent, and Daniel Bengtsson. 2016. "Using Scenarios to Assess Policy Mixes for Resource Efficiency and Eco-Innovation in Different Fiscal Policy Frameworks." Sustainability 8(4). https://doi.org/10.3390/su8040309.

Bristow, Abigail L, Mark Wardman, Alberto M Zanni, and Phani K Chintakayala. 2010. "Public Acceptability of Personal Carbon Trading and Carbon Tax." Ecological Economics 69(9): 1824-37. http://www.sciencedirect.com/science/article/pii/S0921800910001643.

Brunetti, Aymo, and Thomas Straubhaar. 1996. "Direkte Demokratie - Bessere Demokratie? Was Lehrt Uns Das Schweizer Beispiel." Zeitschrift für Politikwissenschaft 6(1): 7-26.

Carson, Richard T, and W Michael Hanemann. 2005. "Chapter 17 Contingent Valuation." Handbook of Environmental Economics 2: 821-936. http://dx.doi.org/10.1016/S1574-0099(05)02017-6.

Cherry, Todd L, Steffen Kallbekken, and Stephan Kroll. 2012. "The Acceptability of Efficiency-Enhancing Environmental Taxes, Subsidies and Regulation: An Experimental Investigation." Environmental Science \& Policy 16: 90-96. http://dx.doi.org/10.1016/j.envsci.2011.11.007.

- - . 2014. "The Impact of Trial Runs on the Acceptability of Environmental Taxes: Experimental Evidence." Resource and Energy Economics 38: 84-95. http://www.sciencedirect.com/science/article/pii/S092876551400058X.

Dargusch, P, and A Griffiths. 2008. "Introduction to Special Issue: A Typology of Environmental Markets." 
Australasian Journal of Environmental Management 15(2): 70-75. https://doi.org/10.1080/14486563.2008.9725186.

Dermont, Clau, Karin Ingold, Lorenz Kammermann, and Isabelle Stadelmann-Steffen. 2017. "Bringing the Policy Making Perspective in: A Political Science Approach to Social Acceptance." Energy Policy 108: 359-68. http://www.sciencedirect.com/science/article/pii/S0301421517303531.

Dowle, Matt, and Arun Srinivasan. 2017. Data.table: Extension of 'data.frame'. https://cran.rproject.org/package=data.table.

Drews, Stefan, and Jeroen C J M van den Bergh. 2016. "What Explains Public Support for Climate Policies? A Review of Empirical and Experimental Studies." Climate Policy 16(7): 855-76. http://dx.doi.org/10.1080/14693062.2015.1058240.

Ekvall, Tomas, Martin Hirschnitz-Garbers, Fabio Eboli, and Aleksander Śniegocki. 2016. "A Systemic and Systematic Approach to the Development of a Policy Mix for Material Resource Efficiency." Sustainability 8(4). https://doi.org/10.3390/su8040373.

Eriksson, Louise, Jörgen Garvill, and Annika M Nordlund. 2008. "Acceptability of Single and Combined Transport Policy Measures: The Importance of Environmental and Policy Specific Beliefs." Research Part A: Policy and Practice 42(8): 1117-28.

European Environment Agency. 2017. Monitoring CO2 Emissions from New Passenger Cars and Vans in 2016. Luxembourg. https://www.eea.europa.eu/publications/co2-emissions-new-cars-and-vans2016.

Federal Office for Spatial Development. 2016. Externe Kosten Und Nutzen Des Verkehrs in Der Schweiz. Strassen-, Schienen-, Luft- Und Schiffsverkehr 2010 Bis 2013.

Federal Office for the Environment. 2017. "CO2 Emissions from Thermal and Motor Fuels." https://www.bafu.admin.ch/bafu/en/home/themen/thema-klima/klima--daten--indikatoren-undkarten/klima--indikatoren/indikator-

klima.pt.html/aHROcHM6Ly93d3cuaW5kaWthdG9yZW4uYWRtaW4uY2gvUHVibG/ljLOFIbURIdGFpb D9pbmQ9SOwwMDEmbG5nPWVu.html (July 6, 2017).

Federal Statistical Office. 2018. "Angenommene Und Verworfene Abstimmungsvorlagen, Nach Typ." https://www.bfs.admin.ch/bfs/de/home/statistiken/kataloge-

datenbanken/tabellen.assetdetail.6666047.html (January 31, 2019).

Felder, Stefan, and Reto Schleiniger. 2002. "Environmental Tax Reform: Efficiency and Political Feasibility." Ecological Economics 42(1): 107-16. http://www.sciencedirect.com/science/article/pii/S092180090200109X.

Fesenfeld, Lukas Paul. 2019. How Policy-Packaging Affects Public Support. Insights from Choice Experiments on Climate Policies in the United States and Germany. Zurich.

Flanagan, Kieron, Elvira Uyarra, and Manuel Laranja. 2010. "The 'policy Mix'for Innovation: Rethinking Innovation Policy in a Multi-Level, Multi-Actor Context." Research Policy 40(5): 702-13. https://ssrn.com/abstract=1629744.

Fox, John. 2003. "Effect Displays in $R$ for Generalised Linear Models." Journal of Statistical Software 8(15). http://www.jstatsoft.org/v08/i15/ (November 4, 2016).

Fox, John, and Jangman Hong. 2009. "Effect Displays in R for Multinomial and Proportional-Odds Logit Models: Extensions to the Effects Package." Journal of Statistical Software 32(1): 1-24. http://onlinelibrary.wiley.com/doi/10.1111/j.1467-

9531.2006.00180.x/abstract\%5Cnhttp://www.jstatsoft.org/v32/i01/ (November 4, 2016).

Freitag, Markus, Adrian Vatter, and Christoph Müller. 2003. "Bremse Oder Gaspedal? Eine Empirische Untersuchung Zur Wirkung Der Direkten Demokratie Auf Den Steuerstaat." Politische Vierteljahresschrift 44(3): 348-69. https://doi.org/10.1007/s11615-003-0068-2.

Givoni, Moshe. 2014. "Addressing Transport Policy Challenges through Policy-Packaging." Transportation Research Part A: Policy and Practice 60: 1-8.

Givoni, Moshe, James Macmillen, David Banister, and Eran Feitelson. 2013. "From Policy Measures to Policy Packages." Transport Reviews 33(1): 1-20. http://dx.doi.org/10.1080/01441647.2012.744779.

de Groot, Judith I M, and Geertje Schuitema. 2012. "How to Make the Unpopular Popular? Policy Characteristics, Social Norms and the Acceptability of Environmental Policies." Environmental Science \& Policy 19: 100-107. http://dx.doi.org/10.1016/j.envsci.2012.03.004.

Gunningham, Neil, and Darren Sinclair. 1999. "Designing Smart Regulation." In A Reader in Environmental Law., ed. Bridget Hutter. Oxford: Oxford University Press, 305-34. 
https://www.oecd.org/env/outreach/33947759.pdf.

---. 2017. Leaders and Laggards: Next-Generation Environmental Regulation. Sheffield: Greenleaf Publishing.

Hahn, Robert W, and Robert N Stavins. 1992. "Economic Incentives for Environmental Protection: Integrating Theory and Practice." The American Economic Review 82(2): 464-68. http://www.jstor.org/stable/2117445.

Hainmueller, Jens, Daniel J Hopkins, and Teppei Yamamoto. 2014. "Causal Inference in Conjoint Analysis: Understanding Multidimensional Choices via Stated Preference Experiments." Political Analysis 22(1): 1. +.

Hansla, André, Erik Hysing, Andreas Nilsson, and Johan Martinsson. 2017. "Explaining Voting Behavior in the Gothenburg Congestion Tax Referendum." Transport Policy 53: 98-106. http://www.sciencedirect.com/science/article/pii/S0967070X16306825.

Howlett, Michael. 2011. Designing Public Policies: Principles and Instruments. London: Routledge.

Howlett, Michael, Yong Pung How, and Pablo del Rio. 2015. "The Parameters of Policy Portfolios: Verticality and Horizontality in Design Spaces and Their Consequences for Policy Mix Formulation." Environment and Planning C: Government and Policy 33(5): 1233-45.

Howlett, Michael, and Jeremy Rayner. 2013. "Patching vs Packaging in Policy Formulation: Assessing Policy Portfolio Design." Politics and Governance 1(2): 170.

Huber, Robert A., Michael Wicki, and Thomas Bernauer. 2019. "Public Support for Environmental Policy Depends on Beliefs Concerning Effectiveness, Intrusiveness, and Fairness." Environmental Politics forthcomin.

Hysing, Erik, and Karolina Isaksson. 2015. "Building Acceptance for Congestion Charges - the Swedish Experiences Compared." Journal of Transport Geography 49: 52-60. http://dx.doi.org/10.1016/j.jtrangeo.2015.10.008.

Jaensirisak, S, Mark Wardman, and A D May. 2005. "Explaining Variations in Public Acceptability of Road Pricing Schemes." Journal of Transport Economics and Policy 39(2): 127-53.

Justen, Andreas, Nils Fearnley, Moshe Givoni, and James Macmillen. 2014. "A Process for Designing Policy Packaging: Ideals and Realities." Transportation Research Part A: Policy and Practice 60: 9-18. https://doi.org/10.1016/j.tra.2013.10.016.

Kachi, Aya, Thomas Bernauer, and Robert Gampfer. 2015. "Climate Policy in Hard Times: Are the Pessimists Right?" Ecological Economics 114: 227-41. http://www.sciencedirect.com/science/article/pii/S0921800915000865.

Kallbekken, Steffen, and Marianne Aasen. 2010. "The Demand for Earmarking: Results from a Focus Group Study." Ecological Economics 69(11): 2183-90. http://linkinghub.elsevier.com/retrieve/pii/S0921800910002284.

Kallbekken, Steffen, Jorge H Garcia, and Kristine Korneliussen. 2013. "Determinants of Public Support for Transport Taxes." Transportation Research Part A: Policy and Practice 58: 67-78.

Kallbekken, Steffen, and Håkon Sælen. 2011. "Public Acceptance for Environmental Taxes: Self-Interest, Environmental and Distributional Concerns." Energy Policy 39(5): 2966-73. http://www.sciencedirect.com/science/article/pii/S0301421511001868.

Kern, F., P. Kivimaa, and M. Martiskainen. 2017. "Policy Packaging or Policy Patching? The Development of Complex Energy Efficiency Policy Mixes." Energy Research and Social Science 23: 11-25. http://dx.doi.org/10.1016/j.erss.2016.11.002.

Kim, Junghwa, Jan-Dirk Schmöcker, Satoshi Fujii, and Robert B Noland. 2013. "Attitudes towards Road Pricing and Environmental Taxation among US and UK Students." Transportation Research Part A: Policy and Practice 48: 50-62.

Kirchgässner, Gebhard, and Friedrich Schneider. 2003. "On the Political Economy of Environmental Policy." Public Choice 115(3): 369-96. https://doi.org/10.1023/A:1024289627887.

Krosnick, Jon A. 1999. "Survey Research." Annual Review of Psychology 50(1): 537-67. https://doi.org/10.1146/annurev.psych.50.1.537.

Lehmann, Paul. 2010. "Justifying a Policy Mix for Pollution Control: A Review of Economic Literature." Journal of Economic Surveys 26(1): 71-97. https://onlinelibrary.wiley.com/doi/abs/10.1111/j.14676419.2010.00628.x.

Leifeld, Philip. 2013. "Texreg: Conversion of Statistical Model Output in R to LaTeX and HTML Tables." Journal of Statistical Software 55(8): 1-24. http://www.jstatsoft.org/v55/i08/. 
Linder, Wolf. 2012. Schweizerische Demokratie: Institutionen, Prozesse, Perspektiven. 3. Auflage. Bern: Haupt Verlag.

Louviere, Jordan J, David Hensher, and Joffre Swait. 2000. Stated Choice Methods. Cambridge University Press. http://econpapers.repec.org/RePEc:cup:cbooks:9780521788304.

Lubell, Mark, Sammy Zahran, and Arnold Vedlitz. 2007. "Collective Action and Citizen Responses to Global Warming." Political Behavior 29(3): 391-413.

Marcucci, Edoardo, Valerio Gatta, Massimo Marciani, and Paola Cossu. 2017. "Measuring the Effects of an Urban Freight Policy Package Defined via a Collaborative Governance Model." Research in Transportation Economics 65: 3-9. http://www.sciencedirect.com/science/article/pii/S0739885917301798.

Mavrot, Céline, Susanne Hadorn, and Fritz Sager. 2018. "Mapping the Mix: Linking Instruments, Settings and Target Groups in the Study of Policy Mixes." Research Policy. http://www.sciencedirect.com/science/article/pii/S0048733318301574.

Milkman, Katherine L. et al. 2012. "Policy Bundling to Overcome Loss Aversion: A Method for Improving Legislative Outcomes." Organizational Behavior and Human Decision Processes 117(1): 158-67. https://www.sciencedirect.com/science/article/pii/S0749597811000793 (June 18, 2018).

Mundell, Robert A. 1962. "The Appropriate Use of Monetary and Fiscal Policy for Internal and External Stability." Staff Papers 9(1): 70-79. https://doi.org/10.2307/3866082.

Nieuwenhuis, Rense, H F te Grotenhuis, and B J Pelzer. 2012. "Influence. ME: Tools for Detecting Influential Data in Mixed Effects Models."

Nissinen, Ari et al. 2015. "Combinations of Policy Instruments to Decrease the Climate Impacts of Housing, Passenger Transport and Food in Finland." Journal of Cleaner Production 107: 455-66. http://www.sciencedirect.com/science/article/pii/S0959652614009184.

Pereira, Á, A Carballo-Penela, A Guerra, and X Vence. 2018. "Designing a Policy Package for the Promotion of Servicising: A Case Study of Vineyard Crop Protection in Galicia (Spain)." Journal of Environmental Planning and Management 61(2): 348-69. https://doi.org/10.1080/09640568.2017.1308317.

Piatkowski, Daniel, Wesley Marshall, and Kevin Krizek. 2017. "Carrots versus Sticks: Assessing Intervention Effectiveness and Implementation Challenges for Active Transport." Journal of Planning Education and

Research:

$1-15$.

http://journals.sagepub.com.libproxy.lib.unc.edu/doi/pdf/10.1177/0739456X17715306.

Pleger, Lyn E. 2017. "Voters' Acceptance of Land Use Policy Measures: A Two-Level Analysis." Land Use Policy 63: 501-13. http://www.sciencedirect.com/science/article/pii/S0264837715302660.

Pleger, Lyn E, Philipp Lutz, and Fritz Sager. 2018. "Public Acceptance of Incentive-Based Spatial Planning Policies: A Framing Experiment." Land Use Policy 73: 225-38. http://www.sciencedirect.com/science/article/pii/S0264837717305215.

$\mathrm{R}$ Core Team. 2015. R: A Language and Environment for Statistical Computing. Vienna, Austria: $\mathrm{R}$ Foundation for Statistical Computing. https://www.r-project.org/.

Raîche, Gilles et al. 2013. "Non-Graphical Solutions for Cattell's Scree Test." Methodology 9(1): 23-29. http://econtent.hogrefe.com/doi/abs/10.1027/1614-2241/a000051.

Rienstra, Sytze A, Piet Rietveld, and Erik T Verhoef. 1999. "The Social Support for Policy Measures in Passenger Transport." Transportation Research Part D: Transport and Environment 4(3): 181-200. http://dx.doi.org/10.1016/S1361-9209(99)00005-X.

Ring, Irene, and David N Barton. 2015. "Economic Instruments in Policy Mixes for Biodiversity Conservation and Ecosystem Governance." Handbook of Ecological Economics: 413-49.

Sælen, Håkon, and Steffen Kallbekken. 2011. "A Choice Experiment on Fuel Taxation and Earmarking in Norway." Ecological Economics 70(11): 2181-90. http://www.sciencedirect.com/science/article/pii/S0921800911002710.

Sager, Fritz. 2007. "Making Transport Policy Work: Polity, Policy, Politics and Systematic Review." Policy \& Politics 35(2): 269-88. https://doi.org/10.1332/030557307780712951.

Sager, Fritz, Karin Mirjam Ingold, and Andreas Balthasar. 2017. Policy-Analyse in Der SchweizBesonderheiten, Theorien, Beispiele. NZZ Libro.

Schade, Jens, and Bernhard Schlag. 2003. "Acceptability of Urban Transport Pricing Strategies." Transportation Research Part F: Traffic Psychology and Behaviour 6(1): 45-61.

Schuitema, Geertje, Linda Steg, and Sonja Forward. 2010. "Explaining Differences in Acceptability before and Acceptance after the Implementation of a Congestion Charge in Stockholm." Transportation 
Research Part A: Policy and Practice 44(2): 99-109. http://www.sciencedirect.com/science/article/pii/S0965856409001256.

Schuitema, Geertje, Linda Steg, and J. A. Rothengatter. 2010. "The Acceptability, Personal Outcome Expectations, and Expected Effects of Transport Pricing Policies." Journal of Environmental Psychology 30(4): 587-93. http://www.sciencedirect.com/science/article/pii/S0272494410000538.

Schulz, Tobias. 2001. Framing Environmental Ballot, Propositions: The Influence of Simultaneous' Pocketbook Measures' and Negative Framing. https://dx.doi.org/10.2139/ssrn.274826.

Sheffer, Lior et al. 2018. "Nonrepresentative Representatives: An Experimental Study of the Decision Making of Elected Politicians." American Political Science Review 112(2): 302-21. https://www.cambridge.org/core/article/nonrepresentative-representatives-an-experimentalstudy-of-the-decision-making-of-elected-politicians/3ABB868FCF033666C9FBC22D7D97F24E.

Sørensen, Claus Hedegaard et al. 2014. "Strategies to Manage Barriers in Policy Formation and Implementation of Road Pricing Packages." Transportation Research Part A: Policy and Practice 60: 40-52. http://www.sciencedirect.com/science/article/pii/S0965856413002012.

Stadelmann-Steffen, Isabelle. 2011. "Citizens as Veto Players: Climate Change Policy and the Constraints of Direct Democracy." Environmental Politics 20(4): 485-507. https://doi.org/10.1080/09644016.2011.589577.

Steg, Linda, Lieke Dreijerink, and Wokje Abrahamse. 2006. "Why Are Energy Policies Acceptable and Effective?" Environment and Behavior 38(1): 92-111. http://journals.sagepub.com/doi/10.1177/0013916505278519.

Stehr, Nico. 2015. "Climate Policy: Democracy is Not an Inconvenience." Nature 525(7570). https://www.nature.com/news/climate-policy-democracy-is-not-an-inconvenience-1.18393.

Stradling, S G, M L Meadows, and S Beatty. 2000. "Helping Drivers out of Their Cars Integrating Transport Policy and Social Psychology for Sustainable Change." Transport Policy 7(3): 207-15. http://www.sciencedirect.com/science/article/pii/S0967070X00000263.

Thalmann, Philippe. 2004. "The Public Acceptance of Green Taxes: 2 Million Voters Express Their Opinion." Public Choice 119(1/2): 179-217. http://link.springer.com/10.1023/B:PUCH.0000024165.18082.db.

Thorpe, Neil, Peter Hills, and Sittha Jaensirisak. 2000. "Public Attitudes to TDM Measures: A Comparative Study." Transport Policy 243-57. http://www.sciencedirect.com/science/article/pii/S0967070X0000007X.

Toepoel, Vera. 2015. Doing Surveys Online. Los Angeles: Sage.

Tsebelis, George. 2002. Veto Players: How Political Institutions Work. Princeton University Press.

Vatter, Adrian. 2016. Das Politische System Der Schweiz. 2., aktual. Baden-Baden: Nomos Verlagsgesellschaft.

Vedung, E. 1998. "Policy Instruments: Typologies and Theories." In Carrots, Sticks, and Sermons: Policy Instruments and Their Evaluation., eds. Marie-Louise Bemelmans-Videc, R. C. Rist, and E. Vedung. New Brunswick, NJ, and London: Transaction Publishers, 21-58.

Vonk, Diana et al. 2014. "Policy Implementation Lessons from Six Road Pricing Cases." Transportation Research Part A: Policy and Practice 172-91. http://www.sciencedirect.com/science/article/pii/S096585641300222X.

Wickham, Hadley. 2009. ggplot2: Elegant Graphics for Data Analysis. New York: Springer New York. http://had.co.nz/ggplot2/book.

- - . 2016. "Tidyr: Easily Tidy Data with Spread () and Gather () Functions." Version 0.6. 0.

- - . 2017. "Forcats: Tools for Working with Categorical Variables (Factors)."

Wickham, Hadley, and Garrett Grolemund. 2017. R for Data Science: Import, Tidy, Transform, Visualize, and Model Data. 1st ed. Sebastopol, CA: O'Reilly Media.

Wlezien, Christopher. 1995. "The Public as Thermostat: Dynamics of Preferences for Spending." American Journal of Political Science 39(4): 981. http://www.jstor.org/stable/2111666?origin=crossref.

World Health Organization. 2008. "MPOWER: A Policy Package to Reverse the Tobacco Epidemic." http://apps.who.int/iris/bitstream/handle/10665/43888/9789241596633_eng.pdf?sequence=1\&is Allowed=y.

Zaslawski, Valerie. 2017. "Keine Pilotversuche. Kantone Bremsen Beim Mobility-Pricing." Neue Zürcher Zeitung. https://www.nzz.ch/schweiz/keine-pilotversuche-kantone-bremsen-beim-mobility-pricingId.1304443\%0A. 
8 Figures and Tables 
Table 1: Conjoint experiment attributes and their characteristics

Attribute

Stricter

Energy

Label

Car and emission information from independent tests.

$\begin{array}{lll}\text { Car } & \text { Current registration rules for cars do not consider emission levels. Under the No: Keep current registratic } \\ \text { Registration } & \text { proposed new rule, registration of new cars would consider emission levels. New Current Registration Rules }\end{array}$

cars with high emissions could not be registered anymore and would thus be Yes: No registration of new cars with high emission levels [Registration Ban] banned.

Road Pricing Current rules for using roads are not considering emissions and driving distances. No: No introduction of such a user fee [No Road Pricing]

Under the proposed new rule, there would be an emission- and kilometre- Yes: Introduction of emission- and kilometre-dependent usage fee [Road Pricing] dependent usage fee, often called road pricing.

Emission Current taxes on cars are considering emissions only in some cantons but not No: Keep current car tax [Keep Current Car Tax]

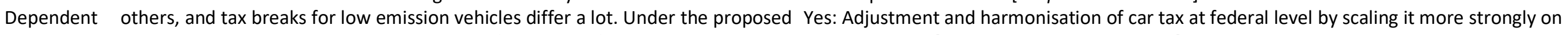
Car Tax new rule, car taxes would be made more uniform at the federal level and would emission levels [Emission Dependent Car Tax] provide stronger tax rebates for low emission cars.

Earmarking Revenues from road pricing and car tax are mainly used for...

$\operatorname{tax}$

revenues

..construction and maintenance of roads [Road Infrastructure]

...construction and maintenance of roads and public transportation infrastructure [Road and

PT Infrastructure]

...general federal budget from which various government expenditures are paid [General Government Budget]

... public transportation subsidies to reduce costs of using it [PT Price Reduction]

Information To enhance the public's understanding of the policy-package, the government No: No accompanying information campaign [No Campaign]

Campaign could launch a nationwide accompanying information campaign to explain the Yes: Switzerland-wide accompanying information campaign [Campaign] contents and benefits of the package and respond to possible public concerns.

Implementa Implementation of the policy-package starting in

2025 [2025]; 2030 [2030]; 2035 [2035]; 2040 [2040]; 2045 [2045]

tion year

Test Phase To enhance the effectiveness of the policy-package, the measures included in it No: Policy-package will be introduced without a test phase [No Test Phase]

and

Evaluation

could be introduced during a two-year test phase. In this test phase, the impacts Yes: Policy-package will be introduced beginning with a two years test phase and its of these measures on society would be examined. These impacts would be evaluation [Test Phase]

evaluated after the two-year test phase. Only then, following this evaluation, a decision would be taken on whether the policy-package will be implemented definitively.

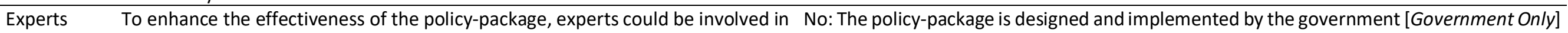
involvement its design and implementation.

Yes: The policy-package is designed and implemented by the government with the involvement of non-governmental experts [Expert involvement]

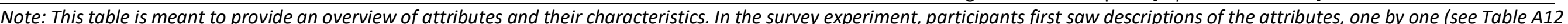

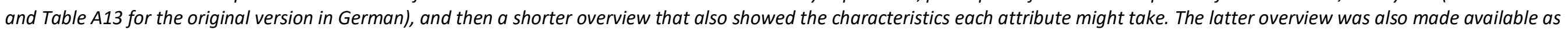

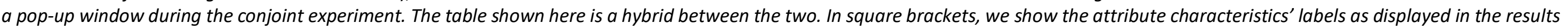

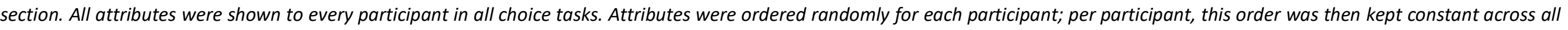
choice tasks. Attribute characteristics were randomly assigned for each choice task. 
What is your view of the two proposals?

\section{Comparison 2 of 5}

\begin{tabular}{|c|c|c|}
\hline & Proposal 1 & Proposal 2 \\
\hline Stricter Energy Label & $\begin{array}{c}\text { Yes: Introduce stricter label to show } \\
\text { independently tested fuel consumption } \\
\text { and exhaust emissions }\end{array}$ & $\begin{array}{c}\text { Yes: Introduce stricter label to show } \\
\text { independently tested fuel consumption } \\
\text { and exhaust emissions }\end{array}$ \\
\hline Car Registration & $\begin{array}{l}\text { No: Keep current registration rules, } \\
\text { without taking emission levels into } \\
\text { account }\end{array}$ & $\begin{array}{l}\text { No: Keep current registration rules, } \\
\text { without taking emission levels into } \\
\text { account }\end{array}$ \\
\hline Road Pricing & $\begin{array}{l}\text { Yes: Introduction of emission- and } \\
\text { kilometre-dependent usage fee }\end{array}$ & No: No introduction of such $a$ user fee \\
\hline $\begin{array}{l}\text { Emission Dependent Car } \\
\text { Tax }\end{array}$ & No: Keep current car tax & $\begin{array}{c}\text { Yes: Adjustment and harmonisation of } \\
\text { car tax at federal level by scaling it more } \\
\text { strongly on emission levels }\end{array}$ \\
\hline $\begin{array}{l}\text { Revenues from Road } \\
\text { Pricing and Car Tax are } \\
\text { mainly used for... } \\
\end{array}$ & $\begin{array}{c}\text {...general federal budget from which } \\
\text { various government expenditures are } \\
\text { paid }\end{array}$ & $\begin{array}{l}\text {...construction and maintenance of } \\
\text { roads }\end{array}$ \\
\hline Information Campaign & $\begin{array}{l}\text { Yes: Switzerland-wide accompanying } \\
\text { information campaign }\end{array}$ & $\begin{array}{l}\text { No: No accompanying information } \\
\text { campaign }\end{array}$ \\
\hline Implementation Year & 2025 & 2045 \\
\hline Test Phase and Evaluation & $\begin{array}{l}\text { No: Policy-package will be introduced } \\
\text { without a test phase }\end{array}$ & $\begin{array}{l}\text { No: Policy-package will be introduced } \\
\text { without a test phase }\end{array}$ \\
\hline Experts Invovlement & $\begin{array}{l}\text { Yes: The policy-package is designed and } \\
\text { implemented by the government with } \\
\text { the involvement of non-governmental } \\
\text { experts }\end{array}$ & $\begin{array}{c}\text { No: The policy-package is designed and } \\
\text { implemented by the government }\end{array}$ \\
\hline
\end{tabular}

If you had to decide: Which of the two proposals would you choose?

O Proposal 1

O Proposal 2

How much do you agree or disagree with proposal 1 ?

strongly

disagree

\begin{tabular}{|llllll|}
\hline & & & & & \\
\hline
\end{tabular}

\section{How much do you agree or disagree with proposal 2?}

strongly
disagree

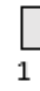

12

4 - undecided

5

Note: translated from German; We use the colour scheme to highlight different types of measures for presentation purposes in this paper only, primary measures are highlighted in light grey, ancillary measures in dark grey, other policy features in white; all attributes appear in every choice task; the characteristics in italic are randomly shown. 


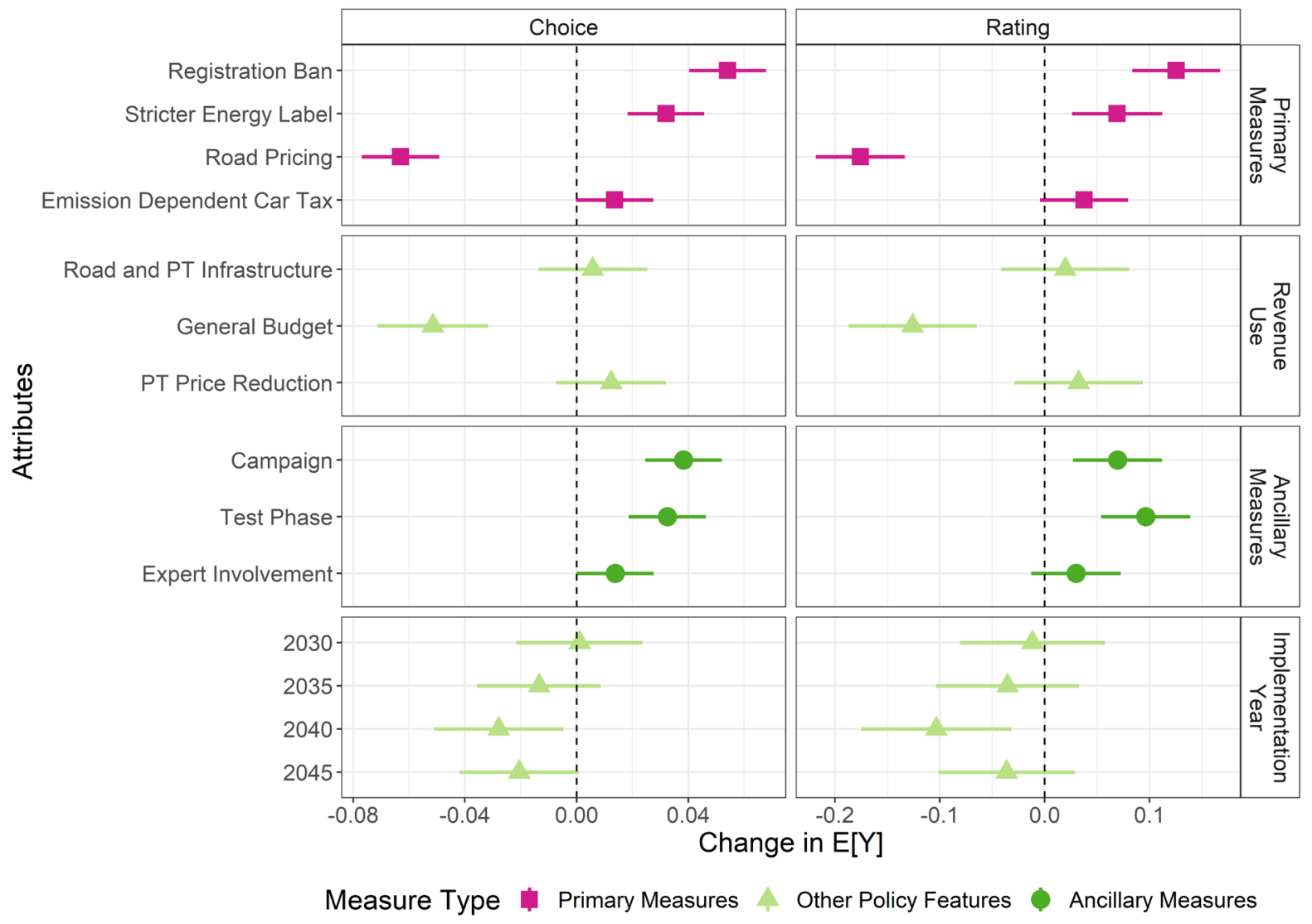

Note: The coefficients for all primary and secondary measures are in relation to excluding the respective measure. For the earmarking, the reference category is 'investment in road infrastructure'. For the implementation date, coefficients are relative to implementation from 2025. 
Figure 3: Predicted likelihood of choosing a policy-package, by primary and ancillary measures included in the package

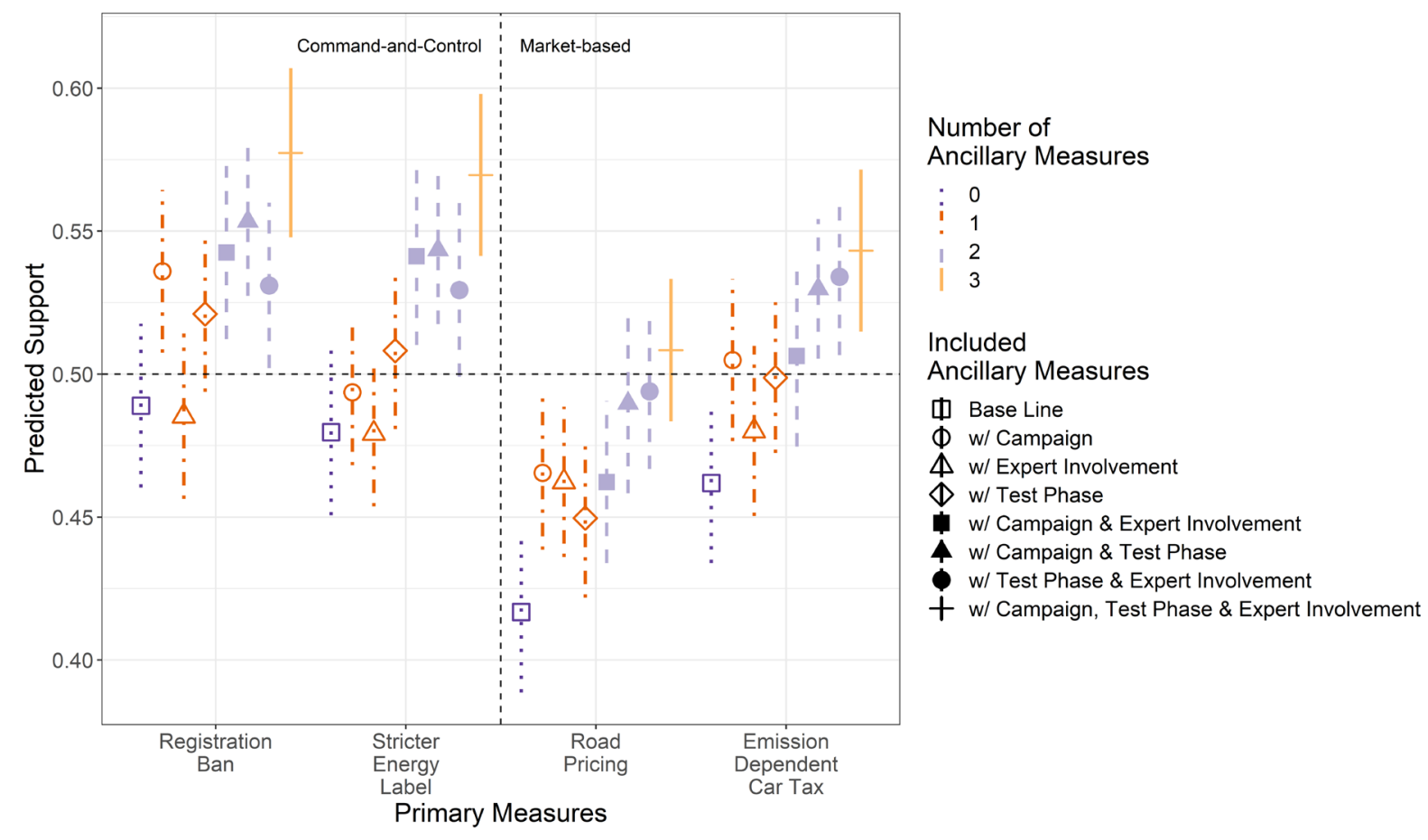

Figure 4: Predicted additional support of policy-packages including one of the four primary measures, depending on the number of ancillary measures included in the package

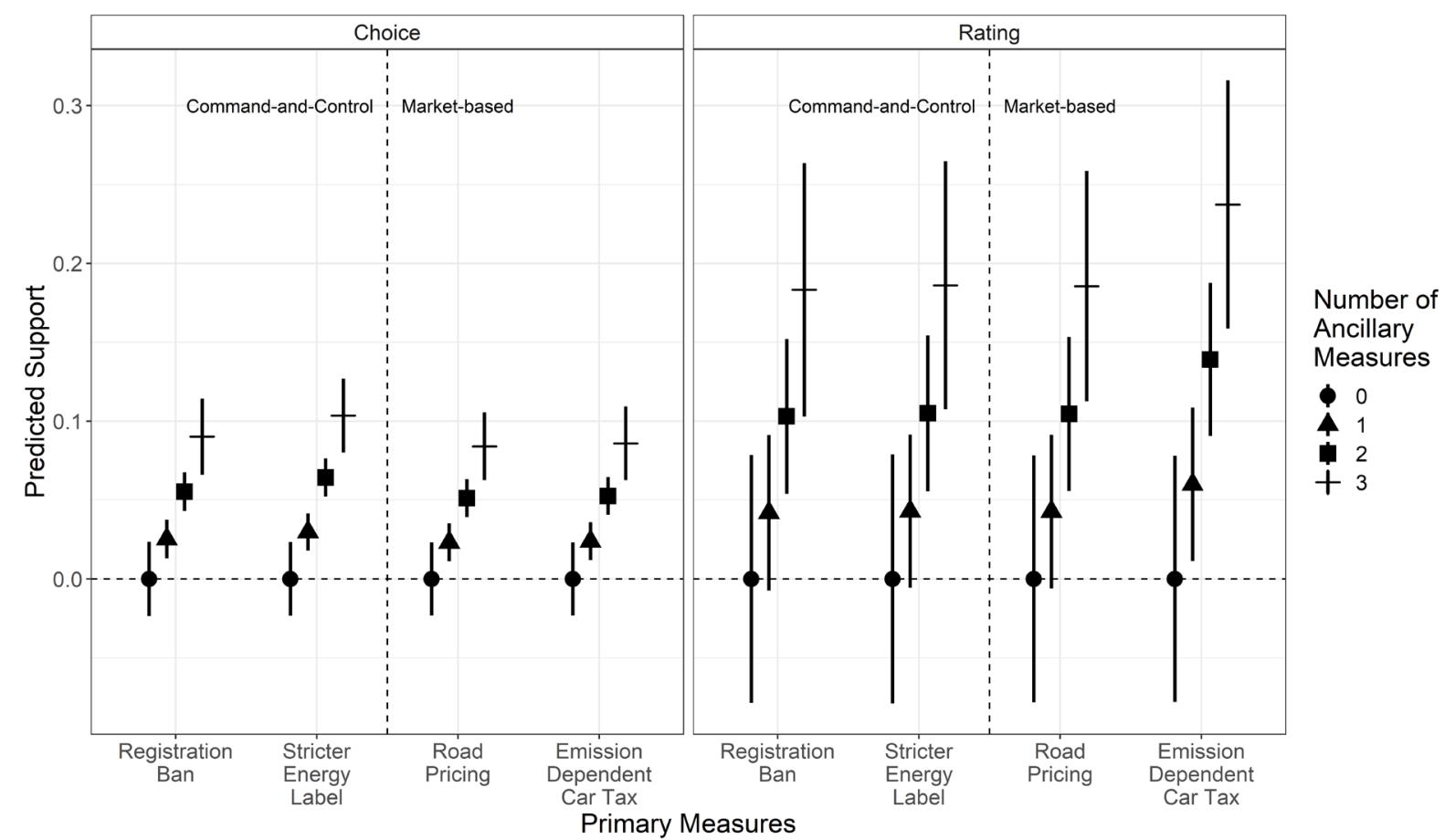

